\title{
Testimonial entitlement, norms of assertion, and privacy
}

\author{
Philip J. Nickel
}

\section{[Forthcoming in Episteme, 2013]}

\begin{abstract}
According to assurance views of testimonial justification, in virtue of the act of testifying a speaker provides an assurance of the truth of what she asserts to the addressee. This assurance provides a special justificatory force and a distinctive normative status to the addressee. It is thought to explain certain asymmetries between addressees and other unintended hearers (bystanders and eavesdroppers), such as the phenomenon that the addressee has a right to blame the speaker for conveying a falsehood but unintended hearers do not, and the phenomenon that the addressee may deflect challenges to his testimonial belief to the speaker but unintended hearers may not. Here I argue that we can do a better job explaining the normative statuses associated with testimony by reference to epistemic norms of assertion and privacy norms. Following Sanford Goldberg, I argue that epistemic norms of assertion, according to which sincere assertion is appropriate only when the asserter possesses certain epistemic goods, can be "put to work" to explain the normative statuses associated with testimony. When these norms are violated, they give hearers the right to blame the speaker, and they also explain why the speaker takes responsibility for the justification of the statement asserted. Norms of privacy, on the other hand, directly exclude eavesdroppers and bystanders from an informational exchange, implying that they have no standing to do many of the things, such as issue challenges or questions to the speaker, that would be normal for conversational participants. This explains asymmetries of normative status associated with testimony in a way logically independent of speaker assurance.
\end{abstract}

\section{Contact Information:}

Philip J. Nickel

p.j.nickel@tue.nl

IPO 1.03

Department of Philosophy and Ethics

School of Innovation Sciences

Eindhoven University of Technology

Postbus 513

5600MB Eindhoven, the Netherlands

\section{Introduction}

Assertion is often directed at a particular hearer, but is this fact important for understanding the epistemology of testimony? ${ }^{1}$ Compare promising. When I promise Cindy that I will meet with Bill, this promise puts Cindy in a privileged position in the sense that

\footnotetext{
${ }^{1}$ I will assume that testimony normally involves something like the act of assertion. Goldberg (2011) defends this claim explicitly.
} 
through the promise she acquires an individualized claim right against me, a right to hold me accountable and to compensation or redress if I fail to meet with Bill. Even if Bill overhears my promise, and even if Bill's interests are set back more seriously than Cindy's by my failure, and even though meeting Bill is what I promise to do, that does not directly give Bill the same right that Cindy has to demand my performance. Such an example shows that a characteristic normative status attached to the speech act of promising is conveyed on a person due to the very fact of her being the intended recipient of the speech act, not due to other factors related to the promise such as being benefited by it or being a participant in its fulfilment. ${ }^{2}$ Directedness is important enough that accounts of the nature of promising must explain it in some way. This raises the question whether directedness is similarly important in the case of assertion. Suppose Al tells Cindy that there is gasoline in the lawnmower, with Bill standing in the vicinity. For comparison's sake suppose that whether there is gasoline in the lawnmower affects Bill just as much or more than it does Cindy. In this second case, does Cindy differ from Bill with respect to an important normative status connected with testimony, and if so, why?

These questions have come up in recent discussions of the epistemology of testimony for two reasons. First, one's entitlement to the beliefs one forms on the basis of testimony is sometimes thought to depend on whether one is the intended recipient of that testimony. The assurance view of testimony holds that the act of telling somebody something characteristically carries with it an assurance or guarantee of the truth of the claim stated, and this assurance or guarantee can be personalized, offered to some hearers but not others. The normative status possessed by the intended recipient of testimony entitles her to believe what

\footnotetext{
${ }^{2}$ This does not imply that the normative statuses of non-recipients such as Bill are unaffected by the promise, only that they are not the same as that of the recipient. For example, Scanlon $(1998,295 \mathrm{ff}$.) stresses that creating expectations in others that they may rely on one's behavior will carry normative consequences even when these expectations are not brought about by a promise. Shiffrin emphasizes that there is a broad human power of commitment which includes both promises and other ways of "induc[ing] morally weighty reliance through communication" $(2008,485)$.
} 
is said because she knows that the speaker personally guarantees the truth of the claim, or implicitly invites the intended hearer's confidence via the act of telling. Like a promise, this guarantee is offered only to the intended recipient, not to bystanders (other hearers who are not the intended recipient), nor to eavesdroppers (others who are meant to be excluded from hearing but are not actually excluded). In particular, the grammar of telling is transitive: one doesn't just tell something, one tells somebody something. Cindy may cite Al's act of assertion as an explicit reason for her belief by saying 'Al told me that there is gasoline in the lawnmower.' As said by Bill, 'Al told Cindy that there is gasoline in the lawnmower' seems to provide a different kind of reason for belief, if it provides any reason at all. Thus it may seem that the intended audience has a privileged entitlement to accept what was said, tied to the assurance that one is personally offered when one is told something.

Second, the distinctive normative status of the intended audience is sometimes thought to account for the character of testimonial entitlement, separating it from other forms of entitlement for belief. For example, Goldberg (2011), a critic of the assurance view, mentions two characteristic phenomena of testimony: first, epistemic buck-passing, in which a hearer who forms a belief $p$ on the basis of a speaker $S$ 's testimony that $p$ may answer thirdparty challenges to that belief by "pass[ing] the epistemic buck on to $S$ (by representing $S$ as having more in the way of epistemic support for the truth of $p$ [than she does])" (178); and second, [testimonial] blame, in which if it turns out that $S$ 's testimony had "insufficient epistemic support" (ibid.), the hearer is entitled to blame $S$ for putting her in a poor epistemic position. Proponents of the assurance view hold that the right to pass the buck to the speaker and the right to blame the speaker are only possessed by the intended audience, and that these rights are connected to the directedness of assurance and of telling.

The assurance view thus draws support from several sources: from the analogy with promising, from its ability to explain the force of testimonial justification and the 
characteristic epistemic statuses associated with it, and from its explanation of our intuitions distinguishing bystanders and eavesdroppers from the intended audience. Although the assurance view is not dominant in the epistemology of testimony, it is worth considering because it places testimony's character as a communicative act at the center of the epistemological account of testimony. It attempts to capture what is distinctive about testimony as a source of belief, grounding it within our communicative practices instead of regarding it as just another species of evidence available to anybody who comes along.

In what follows, I argue that although a special entitlement to belief is conveyed on hearers of testimony, it is not specific to the intended recipient. Drawing on Goldberg (2011), I develop an alternative account of epistemic normative status based on epistemic norms of assertion. On my version of the story, testimonial entitlement is equally enjoyed by intended recipients, bystanders, and eavesdroppers, but buck-passing and testimonial blame are not. Conversational privacy norms clearly distinguish between intended and unintended recipients of testimony, giving intended (non-excluded) hearers the right to ask questions and raise challenges, but not excluded hearers. The assurance view conflates the normative statuses associated with conversational privacy with the epistemic status arising from testimony.

\section{Norm-based epistemic entitlements}

Goldberg (2011) points out that epistemic norms of assertion have broad support in contemporary epistemology and can be can be "put to work" to explain epistemic buckpassing and epistemic blame. Epistemic norms of assertion state that sincere assertion is appropriate only when the asserter possesses certain epistemic goods. Although the exact nature of these epistemic goods is disputed, it is variously held to be a state of knowledge (DeRose 2002, Fricker 2006, Hawthorne 2004, Stanley 2005, Unger 1975, Williamson 2000), 
justified belief (Douven 2006, Gerken 2012, Kvanvig 2009, Lackey 2007) or the truth (Weiner 2005). Goldberg's argument is this. First, testimony always carries with it the force of assertion. Second, assertoric speech acts are held to an epistemic norm of the kind mentioned above: one should never testify unless one has sufficient justification for, or knowledge of, the claim one asserts in so testifying. Third, these first two premises are common knowledge. According to Goldberg, from these three claims we can conclude that a hearer is always justified in holding a speaker to the relevant norm in cases of testimony. Epistemic buck-passing and testimonial blame are part of what constitutes holding a speaker to this norm. They therefore follow from epistemic norms of assertion, and we do not need to posit anything like the assurance view of testimony to explain them.

I wish to make two main points about Goldberg's argument. First, from the premises that a given norm obtains and that this is common knowledge, it does not obviously follow that all persons observing an act falling under the norm are equally entitled to hold the agent to the norm by, e.g., acting on the basis of that agent's performance, or blaming him in case of a norm violation. For example, when the norm of promising obtains and this is common knowledge, it does not follow that anybody observing a promise is equally entitled to hold the promissor to the normative requirement of fulfilling it. The promissee appears to have a special entitlement to do so not possessed by others. When others blame the promissor for non-performance, this is usually done on behalf of the promissee, not on general grounds. For example, suppose A promises $\mathrm{C}$ a bottle of vodka, which would be somewhat detrimental to C's health but not so detrimental as to nullify the norm. If A does not deliver it and C does not complain about this non-performance (because she forgot about the promise, say), it would be strange for some third party to insist that A perform, or to blame A for nonperformance, or to base her own actions on the presupposition of A's performance and hold him accountable for those actions' failure, etc. One could defend a further premise according 
to which the third party would be so entitled, but the original argument is insufficient to establish this. ${ }^{3}$ Similarly, an additional premise stating that the relevant norms of assertion convey equal entitlements (to buck-passing and testimonial blame) on all hearers is needed in Goldberg's argument.

The second main point concerns the argument's conclusion. We can distinguish two kinds of normative statuses to which directedness could be relevant. The first is epistemic entitlement, concerning whether the intended audience has a special epistemic reason for belief (which consists of reasons she in principle possesses or has access to, in a way that is "proprietary"). The second is comprised of other normative statuses characteristic of testimony, such as the entitlement to pass the buck and to blame the testifier. Goldberg's argument concerns the second kind of normative status. Goldberg does not focus on the first kind of normative status because according to him, what makes testimonial justification distinctive is not that it results from a distinctive kind of entitlement or justification possessed by a subject, but that it can be distributed across persons. For Goldberg, distinctly testimonial support for a belief is inherently not (fully) accessible to the hearer herself (because it has to do with the speaker's justification), but nonetheless bears heavily on the hearer's justification (“more than [the hearer]'s own justification does" in Goldberg's (2006) formulation). For Goldberg, it is this anti-individualist fact about testimony that makes testimonial entitlement distinctive, not the nature of the reasons the hearer actually possesses and or has access to. However, we can indeed spell out an argument for a distinctive kind of testimonial entitlement based on epistemic norms of assertion. When a hearer reasonably believes that

\footnotetext{
${ }^{3}$ While criticizing Moran's view, Goldberg claims that the epistemic norm of assertion implies that "a speaker who makes an assertion has performed a speech act that is proper (qua assertion) if and only if the norm was satisfied" and that such a condition "introduces no restriction to intended audience" $(2011,192)$. He concludes that those other than the intended audience get an equal right of complaint. However, a parallel norm of promising can be similarly formulated, but in that case those to whom the promise is not made do not enjoy an equal right of complaint. The formulation of the norm itself does not tell the whole story about who inherits normative statuses regarding its "enforcement." The same point can be made about legal norms: the content of a given norm does not by itself indicate who is allowed to enforce it.
} 
(i) an epistemic norm of assertion obtains in a context; (ii) the speaker is (likely to be) responsive to norms that obtain; (iii) the speaker has asserted $p$, and (iv) the speaker is in a position to know that $p$, and where it can be assumed that there are no further defeaters, then the hearer has an entitlement to believe $p .{ }^{4}$ Let us call this purported form of testimonial entitlement a norm-based (epistemic) entitlement.

The crux of this epistemic entitlement is that the speaker is responsive to relevant norms, and for this proposition to do its work it does not matter who enjoys special, directed rights of complaint or buck-passing and who does not. To see this, it is useful to compare the epistemology of promise-fulfilment. Suppose Bill, in the original promising case from the beginning of the paper, is trying to predict how likely it is that I will meet with him and thereby fulfill my promise to Cindy. Suppose Bill reasonably believes that I am responsive to norms of promising, and that I am therefore quite likely to meet with him because I made a promise to Cindy. For his entitlement to that belief, it does not matter who has the right to hold me to norms of promising. Similarly, when Bill reasons that the lawnmower has gasoline in it because $\mathrm{Al}$ said so, and $\mathrm{Al}$ is responsive to the epistemic norm of assertion, it does not matter who has the right to hold $\mathrm{Al}$ responsible for his statement. I conclude that norm-based epistemic entitlements may be taken advantage of by bystanders or eavesdroppers as well as the intended hearer.

From an epistemic point of view it might seem stupid to rely on presumed compliance with an epistemic norm or rule as a free-standing basis for forming a belief. Norm-based entitlements only go so far. The cases in which I am entitled to form a belief on the basis of an norm-based entitlement are those in which the other available evidence (at least the part of it that I consider) leaves it an open question whether the assertion is likely to be true. The

\footnotetext{
${ }^{4}$ Norm-based entitlements might also require sensitivity to the context, in case the norm of assertion differs from one context to another, as Gerken (2012) argues. Furthermore, if knowledge and justification norms of assertion are qualified by a more fundamental norm requiring experts to have an understanding of what they assert (Carter \& Gordon 2011), then some sensitivity to the more fundamental norm will be required in order to possess the entitlement.
} 
norm-based entitlement is the tipping or decisive consideration. Of course, the other considerations are also, in a sense, tipping or decisive. Neither by itself is sufficient to support an entitlement. Consider an example of Peter Graham's in which he asks us to consider looking through a narrow pipe and seeming to see something, e.g., an apple: "Here your visual experience is focused in on a single object and you have no other information about any other objects and relations before you" $(2006,105) .{ }^{5}$ Graham argues that such a decontextualized perceptual experience confers only defeasible (prima facie), pro tanto justification on the perceptual belief that I form (e.g., "Here is an apple"). It provides only pro tanto justification in the sense that it does not by itself provide the full justification. (Graham contrasts pro tanto justification with “on-balance" justification.) Only when we integrate it with other experiences, memory and beliefs does the experience itself provide a decisive push in favor of entitlement. Similarly, given the norms of assertion, an instance of testimony has a certain force, though not sufficient by itself to provide an on-balance justification for belief. Only when we integrate the testimony with other experiences, memories and beliefs does it provide entitlement.

\section{The Assurance View}

Compare assurance-based epistemic entitlements, as articulated by Hinchman (2005) and Moran (2006), to the norm-based epistemic entitlements I have just described. On the assurance view, an individual act on the part of the speaker, not a rule about assertion, is what entitles a listener or listeners to testimonial entitlement. When a speaker tells something to an audience, as Hinchman describes it, "the speaker acts on an intention to make an epistemic entitlement available to her interlocutor. She intends to make this entitlement available, moreover, simply through his recognition that that's what she intends. It is thus possible ...

\footnotetext{
${ }^{5}$ This is not quite the right description of the situation, since I am aware of the pipe and presumably had a sequence of experiences just before I put my eye up to it. But the point doesn't depend on this.
} 
for a hearer to come to have an entitlement simply by recognizing his interlocutor's intention to make an entitlement available to him" $(2005,564)$. Or as Moran (2006) puts it, "it is essential to the distinctive reason for belief that I get from assertion that it proceeds from something freely undertaken by the other person" $(2006,278)$, viz., an expression of a guarantee that the asserted claim is true. Here, the epistemic status of testimony comes about as a result of a specific speaker-intention associated with the act of assertion. Hinchman describes this as an invitation to trust the speaker; Moran describes it as an assurance. Just as with any other invitation or assurance, it is up to the person doing the inviting to determine to whom it is offered: the intended audience. The status of obvious bystanders or unknown listeners (e.g., in a televised statement) may be unclear, but eavesdroppers are excluded. In some cases it will be clear (e.g., through eye contact, context, etc.) that some hearers are not intended hearers even though they are known to be present. They therefore do not inherit the same entitlement as the intended audience. As a result of these facts, assurance views of testimonial justification imply that the intended hearer is not on the same epistemic footing with bystanders or eavesdroppers. This is the most striking claim of the assurance view and is what makes it an epistemological view rather than a view about conversational norms.

Various secondary asymmetries between the intended hearer and bystanders and eavesdroppers are taken to be intuitive by supporters of the assurance view, and are used to support the theory since they are held to be implied and explained by it. For example it is held that the addressee is licensed to challenge the speaker's assertions, but others are not (Hinchman 2005, 568; Moran 2006, 295). This is because the addressee has been issued an assurance or invitation to trust the speaker, whereas others have not. Another asymmetry is indicated by the fact that if the addressee does not take what is said by the speaker seriously as a reason to form a belief, then he thereby slights the speaker (Hinchman 2005, 565; Moran 2006, 301), whereas this is not true if a bystander or eavesdropper fails to take the speaker's 
claim seriously. This also follows from and is explained by the assurance view, because by an act of assertion the speaker makes her intentions known to the addressee by way of an invitation to trust her, or offers a personal promise or guarantee to the addressee that the claim is true and well-supported. This invitation or guarantee may be rejected or disregarded by the recipient, resulting in a slight. But it may not of course be rejected or disregarded by those to whom it was not offered in the first place, such as other incidental hearers. Such purported asymmetries in secondary status are closely tied with the phenomena of buckpassing and testimonial blame discussed earlier, and together with those they are used to bolster the idea that a special form of epistemic entitlement is conveyed on the intended audience, but not others, through the act of telling.

In the face of such phenomena, I offer two arguments which together counter the assurance view as an epistemological view (of testimonial entitlement). The first argument is that privacy norms provide an alternative explanation of these normative asymmetries. This explanation is compatible with the theory of norm-based epistemic entitlements, and also with the view that any hearer (even eavesdroppers) may obtain an epistemic entitlement even though they do not enjoy other secondary normative statuses equally. The second argument is that norm-based epistemic entitlements are broader (and to some extent, more resilient) than assurance-based entitlements, covering contexts where we do not have much knowledge about the intentions of particular speakers, but where general epistemic norms publicly obtain: for example, in contemporary scientific discourse.

\section{Privacy and directedness}

The first argument starts with the observation that privacy norms determine who is and who is not a part of a conversation, and this explains the asymmetries used to support the assurance view, without claiming that the intended hearer possesses a unique epistemic 
entitlement. When a hearer excluded from a private conversation possesses a norm-based epistemic entitlement based on something said in that conversation, she is prohibited by privacy norms from challenging the speaker or expressing her non-acceptance of his claim. Such a hearer can slight the speaker by refusing to believe him, but she is not entitled to make this refusal known within the conversation, and the speaker is thereby protected from the slight.

In another paper discussing trust-based views of testimonial justification (Nickel 2012), I use privacy norms to explain normative asymmetries between the intended audience and eavesdroppers. However, this does not go far enough to undermine the support that secondary asymmetries provide for the assurance view, because it does not seem that privacy norms prevent bystanders, who are known by the speaker to be listening, from exercising their secondary entitlements. The assurance view draws a sharp distinction between the intended audience and bystanders, since the former but not the latter are offered an invitation or guarantee of the truth of what is asserted. But privacy norms, it would seem, do not draw a distinction between the intended audience and bystanders, because both the intended audience and bystanders (as contrasted with eavesdroppers) are known by the speaker to be listening. What the speaker tells the intended audience is publicly available to the bystander right next to him. It is not private. Hence it would seem that privacy norms cannot explain any asymmetry between them. Furthermore, even if we can establish a privacy difference between speakers and bystanders, the assurance theorist can try to explain this by saying that privacy norms emerge from or are invoked by the act of assurance of the speaker. Hence privacy norms provide no separate explanation of intended audience/bystander asymmetries, but are instead logically “downstream" from the assurance theory’s explanation.

In response, I begin by pointing out that the idea of a testimonial bystander is more difficult to clarify than it might at first seem. If we define a bystander as one who happens to 
hear an utterance not physically pointed in his direction, and who is known by the speaker to have heard it, then this distinction does not define any important difference of normative status. For such a person has all the rights of an addressee. This is acknowledged by defenders of the assurance view. McMyler (2011), who stresses the importance of addressee/ bystander asymmetries for the assurance theory, adopts a principle for distinguishing addressees from bystanders according to which "[i]n performing communicative act $S$, person A addresses person $C$ just in case $A$ intends $C$ to believe that $A$ intends $C$ to understand $S$ " (ibid., letters changed to match those I used earlier), and interprets this principle in such a way that those who happen to overhear something in a public place often turn out to be addressees. According to McMyler, for example, a student who overhears a professor tell another student that the deadline for an assignment has been extended is not a mere bystander but an (indirect) addressee.

But it does not seem that McMyler's distinction between addressee and bystander draws the right line between those who are entitled to challenge or pass the epistemic buck to the speaker and those who are not so entitled. Suppose a professor of American History dislikes student Brad and likes student Coraline, so he purposely speaks in French about the assignment deadline in order that Coraline, a French major, will understand him, while Brad will not be able to. Suppose he is mistaken and Brad is fluent in French. Even though Brad is not an addressee by McMyler's criterion, surely he possesses an entitlement to question, challenge, or refuse to accept the professor's testimony equal to that of Coraline. The reason is that the type of information the professor is offering is inherently public for any student enrolled in the class. Due to dominant informational norms at the university, Brad and Coraline are equally entitled to this information by the relevant publicity norms governing classroom settings — regardless of the professor's intentions. 
Conversely, suppose I overhear a conversation between two doctors in a hospital elevator involving confidential information about a patient. It is clear to all of us that I can hear the conversation. Suppose the doctor speaking intends me to hear and understand her testimony for some reason (perhaps she is trying to impress me), and intends me to be aware of this. In that case, somewhat surprisingly, I am an addressee according to McMyler's criterion. However, privacy norms may exclude me from asking challenging questions of the two doctors or of giving an indication that I have or have not formed a belief on the basis of what they have said. This is because they are having a private conversation, or at any rate one that should be private. Norms of privacy define me as being outside the conversation, because anything else would comprise a violation of patient confidentiality. Privacy norms thus explain the non-exercise of my normative entitlements. As these examples indicate, my standing to exercise my normative entitlements does not have to do with who happens as a matter of fact to hear, nor with those whom the speaker intends to hear, but rather with separate social conventions regarding what is private or confidential and what is not. This defuses the force of the argument for the assurance view from speaker/bystander asymmetries, because it allows us to show that privacy norms dictate these asymmetries.

In order to make this argument stick against the assurance view, it is important that privacy norms have separate explanatory force apart from the speaker assurances associated with assertion. The assurance theorist might try to say that speaker intentions guaranteeing the truth of $p$ directly create both a normative entitlement in the intended audience to believe $p$, and at the very same time invoke privacy norms that exclude others from entitlements such as the right to challenge the assertion or (so to speak) the power to "slight" the speaker by not taking what she says as a reason to believe. The assurance theorist might try to hold, in other words, that speaker intentions normally dictate and give force to privacy norms. But as we see in the two cases above, privacy norms are logically distinct from, and not dictated by, the 
intentions we associate with assertion, although they often overlap with the hearer/bystander distinction and thereby explain the asymmetry intuitions we started with. There is also at least one other obvious reason for thinking privacy norms defining normative statuses in a conversation to be independent of the specific speaker intentions of assertion: other speech acts besides assertion can also be private. Hence the support of these intuitive asymmetries for the assurance view is undermined. ${ }^{6}$

\section{Assurance-based entitlements in practice}

This clears the way for a second argument in favor of norm-based testimonial entitlement and against assurance-based testimonial entitlement. This is that there is a broader range of contexts to which the former is suited, in the sense that the key assumptions on which the entitlement rests are more likely to be fulfilled and withstand critical scrutiny.

Assurance-based epistemic entitlements rest on assumptions about the intentions and acts of particular speakers. Norm-based epistemic entitlements, by contrast, depend on assumptions about the (likely) responsiveness of speakers to epistemic norms of assertion. In some contexts of application, the backing for these two different assumptions overlap: our supposition that a speaker is (likely to be) responsive to epistemic norms of assertion is contiguous with our attribution to him of intentions of sincerity and truthfulness involved in the production of a given speech act. If a close friend makes an apparently sincere assertion, we often have well-justified confidence that he intends not to be careless with the truth or lead us astray, and that his particular speech act reflects this intention. This well-justified

\footnotetext{
${ }^{6}$ An alternative explanation of the asymmetry could conceivably be given in terms of a contextualist account of norms of assertion in which the status of bystander vs. eavesdropper vs. intended audience helps fix the context, and where the relevant norm of assertion for a bystander or an eavesdropper is weaker than that for the intended listener, in such a way that a bystander or eavesdropper has a weaker form of entitlement available in turn. The weaker entitlement would then give rise to a delimited right to blame the speaker or pass the epistemic buck. Although Gerken (2012) makes room for such an explanation by claiming that the deliberative context for assertion is partly fixed by social roles and conventions, he does not spell out the view in this particular way. It is not obvious that the status of bystander/eavesdropper/intended audience would influence the testimonial context in this way, nor whether if it did it would be independent of the very privacy norms I have been discussing. I thank Adam Carter for raising this point.
} 
confidence often derives from the same source as the assumption that the friend is responsive to general epistemic norms of assertion - namely, on the assumption of his good will toward us or care for the truth. Epistemic norms of assertion are largely coincident with more familiar moral norms against lying or "bullshitting," i.e., speaking without care for the truth in the sense of Frankfurt (1988). When we suppose a person is responsive to epistemic norms of assertion, this is sometimes because we attribute an epistemic or a moral motive to him. This same motive also serves as a basis for interpreting his particular speech acts. If it is warranted, it might therefore plausibly support either form of testimonial entitlement.

However, in other contexts such as contemporary scientific discourse, where we do not have much specific knowledge about individual speakers or their intentions but where general epistemic norms are prominently endorsed, discussed, and enforced, providing an additional prudential reason for compliance, we find the right kind of backing for norm-based entitlements but not for assurance-based entitlements. ${ }^{7}$ Testimony in science is based on norms that are explicitly discussed, propounded, and enforced by the community. By contrast, assurance-based entitlements are grounded on the free, intentional acts (of invitation or guarantee) of particular speakers. Assurance-based entitlements are fragile in a way that norm-based entitlements are not, for they make no essential reference to the public, firmly established standards of evidence and truth that govern testimony in the context. It is highly relevant to the likelihood that a scientist's assertions are true that they are subjected to public scrutiny by experts applying stringent norms of evidence for assertions of that kind. By comparison, the fact that the assertions are formed along with the scientist's personal guarantee or invitation to trust is not readily accessible to the recipient of this testimony, and does not provide a resilient reason for belief. When considering whether to accept the testimony of a scientist I do not know at all, and about whom I have only limited contextual

\footnotetext{
${ }^{7}$ I thank Joel Katzav for this point. This assumes these practices are operating effectively. There are, of course, persistent worries and discussion, both among scientists and the public, about whether this is true for (key areas of) contemporary scientific practice.
} 
information, it does not really help me to know that this person offers me a personal guarantee that her statements are true. In this context norm-based entitlements are in a better position to respond to critical doubts than epistemic entitlements based on speaker assurances.

I leave open the possibility that there are some contexts where the assumptions backing assurance-based entitlements are more accessible and defensible than those backing norm-based entitlements. In contexts where compliance with the epistemic norm of assertion seems to be breaking down, or in the case of speakers who have a poor track record of sincerity, it could be the case that we have no other option than to accept a person's implicit guarantee that what she says on a given occasion is true. As an epistemic reason, this is meager: such a guarantee would be unlikely to satisfy a serious critic. But in the absence of further criticism or specific reason to be skeptical, perhaps it offers a reason in favor of belief. In any case, the discussion of the assurance view has not focused on such contexts, and to the extent that other epistemologists have done so, they have disagreed about whether there is any form of epistemic warrant available in them. ${ }^{8}$

\section{References}

Adler, Jonathan. 2010. "Epistemological problems of testimony." In Edward N. Zalta (ed.), The Stanford Encyclopedia of Philosophy. Retrieved December 10, 2012, from http://plato.stanford.edu/archives/win2010/entries/testimony-episprob

Carter, J. Adam \& Gordon, Emma C. 2011. "Norms of assertion: the quantity and quality of epistemic support." Philosophia 39: 615-635.

DeRose, Keith. 2002. “Assertion, knowledge, and context." Philosophical Review 111: 167-203.

Douven, Igor. 2006. “Assertion, knowledge, and rational credibility.” Philosophical Review 115: 449-485.

\footnotetext{
${ }^{8}$ See, e.g., Adler's (2010) discussion of the "Default Rule" for accepting testimony.
} 
Frankfurt, Harry G. 1988. The importance of what we care about. New York: Cambridge University Press.

Fricker, Elizabeth. 2006. "Second-hand knowledge." Philosophy and Phenomenological Research 73: 592-618.

Gerken, Mikkel. 2012. "Discursive justification and skepticism." Synthese 189: 373-394.

Goldberg, Sanford. 2006. "Reductionism and the distinctiveness of testimonial knowledge." In J. Lackey \& E. Sosa (eds.), The Epistemology of Testimony, pp. 127-144. New York: Oxford University Press.

-. 2011. "Putting the norm of assertion to work: the case of testimony." In J. Brown \& H. Cappelen (eds.), Assertion: new philosophical essays, pp. 175-195. New York: Oxford University Press.

Graham, Peter J. 2006. “Liberal fundamentalism and its rivals.” In J. Lackey \& E. Sosa (eds.), The Epistemology of Testimony, pp. 93-115. New York: Oxford University Press.

Hawthorne, John. 2004. Knowledge and lotteries. New York: Oxford University Press.

Hinchman, Edward. 2005. "Telling as inviting to trust." Philosophy and Phenomenological Research 70: 562-587.

Kvanvig, Jonathan. 2009. “Assertion, knowledge and lotteries.” In P. Greenough \& D. Pritchard (eds.), Williamson on Knowledge, pp. 140-160. Oxford: Oxford University Press.

Lackey, Jennifer. 2007. "Norms of assertion.” Noûs 41: 594-626.

McMyler, Benjamin. 2011. "The epistemic significance of address.” Synthese, DOI 10.1007/s11229-011-9871-2.

Moran, Richard. 2006. "Getting told and being believed." In J. Lackey and E. Sosa, eds., The Epistemology of Testimony, pp. 272-306. New York: Oxford University Press.

Nickel, Philip J. 2012. “Trust and testimony.” Pacific Philosophical Quarterly 93: 301316.

Scanlon, T.M. 1998. What we owe to each other. Cambridge, MA: Harvard Belknap.

Shiffrin, Seana Valentine. 2008. "Promising, intimate relationships, and conventionalism." Philosophical Review 117: 481-524.

Stanley, Jason. 2005. Knowledge and practical interests. Oxford: Oxford University Press.

Unger, Peter. 1975. Ignorance. Oxford: Oxford University Press. 
Weiner, Matthew. 2005. "Must we know what we say?" Philosophical Review 114: 227251.

Williamson, Timothy. 2000. Knowledge and its limits. New York: Oxford University Press.

Academic biography: Philip Nickel is Assistant Professor in the Department of Philosophy and Ethics in the School of Innovation Sciences at Eindhoven University of Technology. He moved to the Netherlands from the USA in 2008. He is the author of articles on trust, testimony, the ethics of belief, and the ethics of technology. 